\title{
Influence of Organizational Care and Support on Emotional and Behavioral Problems of Sheltered Street Children
}

\author{
Sarvani $^{1}$
}

\section{ABSTRACT}

The present study is to find out the influence of organizational care and support on emotional and behavioral problems of sheltered street children. The sample consist 444 respondents. 176 are from government shelters, and 268 are from non $\neg$ government shelters. For this purpose of investigation Revised Youth Self Report (RYSR), which is a revised form of Youth Self Report (YSR) is an English form of age 11-18 years, devised by Achenbach and Rescorla (2001) and Organizational care and support developed by researcher were used. The data obtained were analyzed through t- test to know the mean difference between the government and non government groups. The street children in government shelters have more behavioral problems such as anxiety, withdrawal, somatic problems, social problems, thought problems, attention problems, rule breaking behavior and aggression than non government sheltered street children. Government sheltered street children have more health problems, and less social support than non government sheltered street children.

Keywords: Street Children, Emotion, Behavior, Organization, Government and Non Government

Children roaming in the streets of various towns and cities are a growing concern in contemporary world, particularly in India and other developing countries. There are 50 million street children in South America and 25 to 30 million in Asia and the remaining are in Africa. This number is growing fast in alarming proportions. In general, all cities in developing countries have experienced population explosion, including Lagos, Mumbai, Mexico City, Sao Paulo, Rio de Janeiro and Djakarta. In India there are about 100,000- 125,000 street children in Mumbai. Kolkata and Delhi while 45,000 are in Bangalore, (www, emdh.org).

Evidence from further researches show that, about 18 million children work on the streets of India and only 5-20 percent of them are truly homeless and disconnected from their families. Because the street children in India have unique vulnerabilities -the amount of time they spend on the street, their livelihood depending on the street, and their lack of protection and care from adults - they are a sub group of the Indian population that deserve specific attention in order to

${ }^{1}$ Lecturer, Dr. L.B College of Education, India

(C) 2015 I Sarvani; licensee IJIP. This is an Open Access Research distributed under the terms of the Creative Commons Attribution License (http://creativecommons.org/licenses/by/2.0), which permits unrestricted use, distribution, and reproduction in any Medium, provided the original work is properly cited. 


\section{Influence of Organizational Care and Support on Emotional and Behavioral Problems of Sheltered Street Children}

ensure that their needs are known. As the most vulnerable group of children in India according to UNICEF, they need to be understood as much as possible.

United Nations International Children's Emergency Relief fund (UNICEF1988), describes street children in the following manner: The term denotes not only a place of congregation, but also a certain set of working and living conditions. The vast majorities are on the street to make a living for their families and / or themselves for these children, the street is, above all, a work place. Second, they spend most of the time on the streets, frequently because of their low returns on their labor. Third, most r.u.ke then- way into the informal sector as petty hawkers, shoeshine boys, scavengers of raw materials or even thieves and street prostitutes. Fourth, by the nature of their work and life, they are normally on their own, largely unprotected by adults.

In shelters of government and non-government organizations, the field workers collect the children from the neighboring places and enroll them in the shelters. Sometimes public and police also enroll street children; it also happens that parents enroll their children because the children wander on roads. A 24hrs telephone helpline known as CHILDLINE provides emotional assistance to street children and through this CHILDLINE, some children are referred to the shelters.

\section{CAUSES FOR A CHILD TURNING AS A STREET CHILD}

There are different sets of factors that may prompt a child to leave home at an early age. These factors could be broadly grouped into four categories like

a) Economic factors such as poverty, a low standard of living, the child being sent to work at an early age.

b) Familial factors such as conflicts in the family, having a step-parent who is abusive, lack of love and attention.

c) Social factors such as pressure from peers to move away from home, attraction of city life as compared to the life of the rural areas.

d) Psychological factors such as the need to assert one's independence, the need for more attention, and so on. Causes for street children are elaborated further.

\section{EMOTIONAL AND BEHAVIORAL PROBLEMS OF STREET CHILDREN}

Most of the street children are exposed to physical illnesses and psychologically neglected to the extent that they cannot develop adequately (Van Rooyen et a/, 2002).

\section{Psychopathology}

Available literature indicates that street youths are more vulnerable to impaired psychological health than any other group of youths, it was found that $30-40 \%$ of street youths report depression, a high prevalence of paranoid ideation, conduct disorder and attempted suicide (Adlaf \& Zdanowicz, 1999). 


\section{Influence of Organizational Care and Support on Emotional and Behavioral Problems of Sheltered Street Children}

This was underscored by a longitudinal study conducted by Vostanis, Grattan \& Cumella (1998)on street youths in London, which revealed that developmental delays (gross motor skills, personal and social impairments), and learning difficulties are common among street youths. A higher rate of behavioral problems such as sleep problems, aggression, over-activity, shyness, withdrawal and emotional problems such as depression, anxiety, sadness, low self-esteem and self harm (scratching, head banging, punching, etc.) was also common. It was found that comorbid features were also common including conduct disorders, attention deficit disorder, hyper activity disorder and obsessive compulsive disorders (Bassuk \& Rubin 1987).

Another study on depression and stress in street youths in Canada revealed that depression can be linked to homelessness and the stressors inherent in street life, including lack of shelter, food and basic needs, abuse, emotional abuse, pregnancy, HIV, lack of social support, family stress and ineffective coping methods (Ayerst, 1999). This was further confirmed in a study conducted by Holford (1998) who found that there are many psychological disturbances in street youths including high levels of stress, and anxiety and tension which result in adrenal imbalances, mood swings, aggression irritability, restlessness, depression and hyperactivity (Holford, 1998 in Geldenhuys, 2001) Moreover, Geldenhuys' (2001) study indicated that street youths may also experience feelings of hopelessness, inferiority, despondency, rebellion, feelings of uncertainty about life in general and rage, rejection and desertion as a result of their circumstances.

Yates (1991) pointed out that street youths are more likely to be clinically depressed and twice as likely to be actively suicidal or to have attempted suicide previously, with many of these youths seeing suicide as the only solution to their distress and hardships. Similar observations were made by Klain (1999), who found that many street youths are more likely to have personality disorders due to their need to create different identities in order to survive on the streets. As a result, they use distancing and dissociative behaviors

Street children are there in every country and almost every city in the world. For some regions, it has been a familiar phenomenon for a long time, while for others it has emerged only in the last decade (Le Roux, 1995). Problems arising in the social milieu as well as economic and political upheaval are some of the major causes for psychological problems of these children (Schurink \& Tiba, 1993).

Whitbeck, Les B. et al. (2004) observed that homeless and runaway adolescents report significant levels of mental disorder and co-morbidity that are comparable and often exceed the levels reported in studies of larger magnet cities Michael et al. (2007) studied high rates of physical and emotional problems in a population of street children, many of whom were still connected to their families, emphasize the importance of developing different approaches for children with different vulnerabilities. This study also demonstrates the feasibility of embedding on-going field research into the service dimension of "front-line" social care agencies. 


\section{Influence of Organizational Care and Support on Emotional and Behavioral Problems of Sheltered Street Children}

Sandra L. Ayerst (2003) examined that stress and depression were positively correlated in case of the street youth and that these youth had higher levels of depression compared to nonrunaways. There were also differences in coping strategies: street youth were more likely to engage in acts of self-harm and to use drugs and alcohol, while non-runaways more frequently resorted to productive problem solving and disclosure/discussion with someone they trust.

Anooshianm, Linda J. (2005) examined the role of violence and aggression in the lives of children in homeless families, focusing on possible connections among family violence, children's aggression, and children's problems with social isolation and rejection. Chen, X. et al. (2007) showed that youth with childhood onset are more likely to engage in a series of antisocial behaviors such as use of sexual and nonsexual survival strategies. Secondly, the youth with childhood-onset conduct disorder are more likely to experience violent victimization.

Votta, Elizabeth, and Manion, I. (2004) studied that homeless youth reported a higher prevalence of suicidal ideation, past suicide attempts, depressive symptomatology and internalizing and externalizing behavior problems. Findings also indicate that homeless youth reported greater use of a disengaging coping style than the non-homeless youth and are more prone for high-risk behaviors.

\section{Perceived organization support for sheltered street children}

Shelters run by the government and non-government organizations provide care, protection, support, education, development, employment, and rehabilitation of street children. Street children shelters are preferred over adult shelters and street outreach encourages youth to seek help when they might otherwise stay on the street. Mentors provide sympathetic listening and encouragement, as many youth are without a caring adult in their lives. Counseling helps the youth come to terms with painful life experiences

Hackman \& Marcia Jean (2002) explored the process of homeless youth leaving street life and becoming independent. It is reported that moving to a shelter where they can have a safe environment in which they can self examine their past and present circumstances is quite welcome. They try to contemplate on what kind of future they would like to have. Lam, Debbie \& Cheng, Fucai (2008) examined the effectiveness of the government-managed Protection and education centre for street children in Shanghai. The study shows that most of the street children disliked the high security of the centre and many had rejected going home.

Cowan, Beryl Ann (2008)found that lifetime trauma exposure and homeless specific complex stress independently accounted for a significant amount of the variance in symptoms of depression, anxiety, aggression, and post traumatic stress. Life time trauma alone accounted for the variance in anger and anxiety related symptomatology. Gewirtz et al. (2008) proposed that 


\section{Influence of Organizational Care and Support on Emotional and Behavioral Problems of Sheltered Street Children}

supportive housing provides a valuable but hitherto under used opportunity to support children's psychosocial functioning.

\section{SCOPE}

In India there are a number of shelters for street children in many cities. However, the shelters located in Hyderabad and Vijayawada are promising Hyderabad is one of the largest metropolitan cities in India. As the city developed in all areas i.e. Information technology, industries, Whole sale markets and real estate etc, many opportunities are available for people to make their life comfortable Vijayawada is another major city and is a main railway junction. The city assumed a lot of commercial importance due to textile trade and agriculture. Many street children migrate to these cities lured by the city life and most of them seek shelter in any government or nongovernment organizations. As the services of these shelters are promising, the study has been confined to these two cities.

\section{OBJECTIVE OF THE STUDY:}

- To examine the emotional and behavioral problems between sheltered street children in government and non -government.

- To examine the organizational care and support between sheltered street children in government and non -government.

\section{Sample:}

The sample for the present study belongs to the lower socio economic status with similar background in family living style has been chosen. The sampling procedure adopted is more or less purposive. Out of the total 444 respondents, 176 are from government shelters and 268 are from non-government shelters. The average mean age of the participants is about 17.

\section{Tools}

In the present study

- $\quad$ Revised Youth Self Report (RYSR), which is a revised form of Youth Self Report (YSR) is an English form of age 11-18 years, devised by Achenbach and Rescorla (2001); the Telugu version of the same was developed by Ramana (2006).

- Organizational care and support developed by researcher The items Of aspects in the questionnaire are classified into six categories; viz., physical facilities, educational facilities, health problems social support peer group support and moral support A total of 55 items were selected for their diversity in relevance to organizational care and support Each item was represented as a single statement. Respondents were asked to rate each item on a five point likert scale- where a score of 'one' indicates strongly disagree and 'five' indicates strongly agree, with intermediary scores of undecided. Reverse scoring was given for some of the negative statements present in the questionnaire. 


\section{RESULTS}

An attempt was made to present a comparison between government and nongovernment shelters of street children on emotional and behavioral problems as well as the organizational care and support. The sample was divided broadly into two groups - the government shelters for street children and the non-government shelters for street children. For convenience, abbreviations such as GOVT for government shelters and NGO for non-government shelters have been used in the present discussion.

\section{EMOTIONAL AND BEHAVIORAL PROBLEMS}

It has been observed that all the dimensions of emotional and behavioral problems differed significantly across the GOVT and NGO shelters.

\section{Anxiety/ Depressed}

With regard to the difference on anxiety/ depressed dimension, it was observed that the street children in GOVT shelters have higher scores on anxiety/depressed $(t=7.602 ; \mathrm{p}<0.01)$ than in NGO shelters (Table-1). The street children in GOVT shelters have anxiety disorders due to lack of basic needs and physical abuse by others. Children with Anxiety disorder may perceive events of threatening, feel like to be in the unpleasant situations with depressed behavior. The street children in NGO Shelters have lower scores on anxiety disorder as compared to the street children in GOVT shelters, because of fulfilling of basic needs besides adequate care and support.

Findings of a recent research study by Gustafson, Debra K. (2007) support above observations. Results of the study demonstrate that, both increased life stressors and decreased coping efficacy predicted greater child anxiety. Coping efficacy did not moderate the relationship between children's life stressors and number of worries, worry intensity or level of anxiety. Additionally, regulated coping significantly moderated the relationship between life stressors and child anxiety indicating that children with low regulated coping were more vulnerable to the effects of stress as related to anxiety.

\section{Withdrawal / Depressed}

The street children living in GOVT shelters have significantly higher scores on withdrawal / depressed $(£=5.342 ; \mathrm{p}<0.01)$, than the street children in NGO shelters (Table-1). It can be explained that the street children in GOVT shelters have more withdrawal behavior due to lack of social interaction with others and not being exposed to the society. Their social skills may not be on par with other children. This would lead to experience of loneliness which put them into daydreaming, fearful of things without reason, besides frequent complaint of being sick and go into deep bouts of depression. It is observed that old-fashioned approach of institutionalizing street children in custodial care (often through juvenile justice system) is not an appropriate or effective intervention In almost all the GOVT shelters, the drop out of the street children is due 


\section{Influence of Organizational Care and Support on Emotional and Behavioral Problems of Sheltered Street Children}

to custodian care, through Juvenile Justice System. Sometimes these withdrawn practices may lead to antisocial behavior and these children may fall in the dangerous environment for not being socialized with adequate freedom. It is found that the street children in NGO shelters have lower scores of withdrawn behavior compared to street children in GOVT shelters. These children may get the opportunity of being socialized with other children in the surroundings of their shelters. Thus, they mingle with other children and make friendship with them, which may help them to bring change in themselves.

\section{Somatic complaints}

The mean scores of these two groups indicated that the street children in GOVT shelters have higher scores on somatic complaints $(t=5.155 ; \mathrm{p}<0.01)$ than the street children in NGO shelters (Table-1). The street children in GOVT shelters have somatic complaints such as skin disorders, dental problems, visual problems and physical illness etc. This may be due to malnutrition and unhygienic conditions delayed medical facilities and lack of health consciousness. In GOVT shelters because of administrative delay, the facilities may not be provided on time, mainly due to delay of releasing funds from GOVT. Street children in NGO shelters have lower scores in somatic problems when compare to the GOVT shelters.

\section{Social problems}

Regarding the difference in the dimension of social problems, it was observed that the street children in GOVT shelters differ significantly compared to the street children in NGO shelters, exhibiting higher scores on social problems $(t=5.995 ; \mathrm{p}<0.01)$ (Tablel-1). Street children in the GOVT shelters have social problems such as dependency and loneliness are developed due to lack of confidence in social situations, depressive feelings, feeling of isolation, feeling of inferiority, attributes towards friendship and relationship with others. The above socio-psychological problems are attributed to their environment in custodial care (often through juvenile justice system). The street children in NGO shelters have lower scores in social problems compared to the street children in GOVT shelters. This may be due to the fact that, they continue their education in public schools and in this process, they mingle with non street children and are better exposed to society, thereby they gain social awareness. As they develop and maintain relationship with normal children, they continue to improve their social skills 
Table-1, Difference between GOVT and NGO shelters of street children on emotional and behavioral problems

\begin{tabular}{|c|c|c|c|c|}
\hline Behavioral problems & Organization & Mean & S.D & $t$-value \\
\hline \multirow[t]{2}{*}{ Anxiety/depressed } & GOVT & 13.41 & 5.48 & \multirow{2}{*}{$7.60 * *$} \\
\hline & NGO & 9.34 & 5.53 & \\
\hline \multirow[t]{2}{*}{ Withdrawal/depressed } & GOVT & 8.62 & 3.56 & \multirow[t]{2}{*}{$5.34 * *$} \\
\hline & NGO & 6.69 & 3.80 & \\
\hline \multirow{2}{*}{ Somatic complaints } & GOVT & 7.82 & 4.98 & \multirow[t]{2}{*}{$5.15^{* *}$} \\
\hline & NGO & 5.35 & 4.86 & \\
\hline \multirow[t]{2}{*}{ Social problems } & GOVT & 11.48 & 5.15 & \multirow[t]{2}{*}{$5.99 * *$} \\
\hline & NGO & 8.41 & 5.31 & \\
\hline \multirow[t]{2}{*}{ Thought problems } & GOVT & 11.11 & 5.53 & \multirow[t]{2}{*}{$5.55^{* *}$} \\
\hline & NGO & 7.93 & 6.10 & \\
\hline \multirow[t]{2}{*}{ Attention problems } & GOVT & 9.33 & 3.96 & \multirow[t]{2}{*}{$5.81 * *$} \\
\hline & NGO & 6.90 & 4.51 & \\
\hline \multirow[t]{2}{*}{ Rule breaking behavior } & GOVT & 15.05 & 7.18 & \multirow[b]{2}{*}{$5.79 * *$} \\
\hline & NGO & 1119 & 657 & \\
\hline \multirow[b]{2}{*}{ Aggressive Behavior } & GOVT & 1757 & 765 & \multirow[b]{2}{*}{$4.52 * *$} \\
\hline & NGO & 1402 & 830 & \\
\hline
\end{tabular}

Sample size: GOVT=176; NGO=268 ${ }^{*} \mathrm{p}<.05,{ }^{* *} \mathrm{p}<.01$

\section{Thought problems}

The street children in GOVT shelters have higher scores on thought problems ( $t=5$. 52; $p<0.01$ ) than the street children in NGO shelters (Table-1).The street children in GOVT shelters have thought problems such as strange behavior, repetitive acts and sleeping problems etc. These problems are more subjective in terms and are experienced by the individual himself. Disturbed families, ill health, tendencies towards imagination daydreaming and attitude towards 


\section{Influence of Organizational Care and Support on Emotional and Behavioral Problems of Sheltered Street Children}

relationship with others may be the main causes of thought problems. The street children in NGO shelters have lower scores in thought problems when compared to the street children in GOVT shelters, because of the care and support in NGO shelters.

\section{Attention problems}

With regard to the difference in attention problems, it is observed that the street children in GOVT shelters have higher scores $(t=5.815 ; \mathrm{p}<0.01)$ than the street children in NGO shelters (Table-1). The street children in GOVT shelters have attention problems such as daydreaming, in attentiveness, impulsivity, confusion and low levels of self- confidence in social situation. It so happens due to disturbed family experiences such as divorced parents, parental rejection, sibling rivalry, parental abuse etc. The street children in NGO shelters have low score on attention problems as they are properly engaged in their academics and extracurricular activities.

\section{Rule breaking behavior}

Regarding the difference in the dimension of rule breaking behavior, it is found that street children in GOVT shelters have higher scores on rule breaking behavior $(t=5.796 ; p<0.01)$ than their counter parts in NGO shelters (Table-1). The street children in GOVT shelters have rule breaking behavior in the form of involving in bad friendships, tendency to run away from home and breaking the rules very often. This is mainly due to disturbances in the family, poor health, feeling of insecurity, feeling of inferiority, depression and unfavorable attitudes developed towards relationship with others. In the NGO shelters, children have lower scores, as they get effective interventions of developing positive attitude, trust and relationship, developing morals above all these decrease rule breaking behavior.

\section{Aggressive behavior}

It is evident from Table that, street children in GOVT shelters have higher scores on aggressive behavior ( $\mathrm{t}=4.528$; $\mathrm{p}<0.01$ ) compared to the street children in NGO shelters. Street children in GOVT shelters have aggressive behavior due to their exposure to violent patterns such as more stubbornness, argumentative, tendency of fight with others and thus tend to destroy things. It all happens due to over vigilance, strictness, giving strong punishments and custodial care in the GOVT shelters. Whereas children in NGO shelters have lower scores of aggression because of affordable approach, freedom of movement and friendly atmosphere that may decrease their aggressive behavior.

A study conducted by Booth RE, Zhang Y. (1996) supports the above observations. The study revealed that severe aggressive behavior was associated with other problematic behaviors like attempted suicide, behavior that precipitated residential psychiatric treatment, pregnancy, arrests and convictions. The assessment and systematic treatment of conduct disorders and aggression among runaway and homeless youths is urgently needed to reduce the effects of the disorder and associated problem behaviors. 


\section{Influence of Organizational Care and Support on Emotional and Behavioral Problems of Sheltered Street Children}

Another study that supports the view is done by Anooshian, Linda J. (2005), who reported that family violence and economic distress contributed to problematic aggressive behaviors among children that aggression, in turn, appeared to lead to social isolation and avoidance.

\section{ORGANIZATIONAL CARE AND SUPPORT}

Organizational care and support is one of the important factors, which positively influence the lives of the street children. It has been observed that only three out of seven factors affect the life of street children, they are (i) health problems, (ii) organizational facilities and (iii) social support. The difference with regard to the remaining four factors - (i) physical facilities, (ii) schooling, (iii) organizational procedures and (iv) peer group support are not significant because these factors indicate similar attributes in both the shelters. In this section influence of first three factors mentioned above that revealed significant difference in organizational care and support discussed.

\section{Health problems}

Street children in the GOVT shelters have health problems viz., visual, hearing dental, skin, physical illness and sleeping problems. It is observed that street children in GOVT shelters have high score on health problems $(t=4.169 ; \mathrm{p}<0$ 01) than the street children in NGO shelters (Table1). Street children in the GOVT shelters are facing high rate of health problems due to malnutrition, unhygienic conditions and lack of health consciousness. Street children in the NGO shelters have lesser health problems due to the provision of nutritious food, hygienic environment and developing healthy habits by attending health awareness programs.

One recent study by Zena, A. and Aneth, K. (2010) supports the above observations. This study revealed that, street children frequently experience illness, particularly fever, skin diseases, injuries, headaches, diarrhea and stomach upsets

\section{Organizational facilities}

The mean values indicate that the street children in GOVT shelters have more organizational facilities $(t=2.31 ; \mathrm{p}<0$ 05) than street children in NGO shelters (Table-2). Street children in GOVT shelters are being provided with organizational facilities such as vocational training and guidance \& counseling. Street children in the NGO shelters do not have such organizational facilities. Although some NGO shelters provide guidance \& counseling and library facilities, they are not at an adequate level. 
Influence of Organizational Care and Support on Emotional and Behavioral Problems of Sheltered Street Children

Table- 2, Difference between GOVT and NGO shelters of street children on the organization care and Support

\begin{tabular}{|c|c|c|c|c|}
\hline \begin{tabular}{|c|} 
Organization care \\
support
\end{tabular} & \begin{tabular}{l|l|} 
Organization \\
\end{tabular} & Mean & SD & t-Value \\
\hline \multirow[t]{2}{*}{ Physical facilities } & GOVT & 43.34 & 6.17 & \multirow[b]{2}{*}{0.27} \\
\hline & NGO & 43.17 & 6.36 & \\
\hline \multirow[t]{2}{*}{ Schooling } & GOVT & 25.02 & 5.32 & \multirow[b]{2}{*}{1.30} \\
\hline & NGO & 24.35 & 5.36 & \\
\hline \multirow[t]{2}{*}{ Health problems } & GOVT & 1578 & 7.11 & \multirow{2}{*}{$4.16^{* *}$} \\
\hline & NGO & 13.01 & 6.63 & \\
\hline \multirow{2}{*}{$\begin{array}{l}\text { Organization al } \\
\text { procedures }\end{array}$} & GOVT & 33.80 & 5.85 & \multirow[b]{2}{*}{0.10} \\
\hline & NGO & 33.74 & 5.33 & \\
\hline \multirow[t]{2}{*}{ Peer group support } & GOVT & 25.01 & 455 & \multirow[b]{2}{*}{-0.18} \\
\hline & NGO & 25.08 & 3.72 & \\
\hline Organizational & GOVT & 20.56 & 417 & \multirow[b]{2}{*}{$2.31^{*}$} \\
\hline facilities & NGO & 19.54 & 478 & \\
\hline Social & GOVT & 26.94 & 5.63 & \multirow{2}{*}{$-3.48 * *$} \\
\hline support & NGO & 28.60 & 434 & \\
\hline
\end{tabular}

Sample size GOVT $=176, \mathrm{NGO}=268{ }^{*} \mathrm{p}<.05,{ }^{* *} \mathrm{p}<.01$

\section{Social support}

Street children in both the GOVT and NGO shelters are differ significantly with regard to the social support Street children in NGO shelters are reporting more social support $(\mathrm{t}=3.48 ; \mathrm{p}<0$ 01) than the street children in GOVT shelters (Table). The street children in NGO shelters perceive more social support in the form of sharing feelings, taking advices and suggestions from friends, teachers and warden. Thus, these children are more enthusiastic, encouraging and helping each other. They bother about other problems and never exhibit any discrimination among themselves. On the other hand, street children in GOVT shelters have less social support because of the employees in GOVT shelters are permanent job holders and may not show commitment to serve children and extend support. Custodial care (often through juvenile justice system) may not provide required social support to the children. 


\section{Influence of Organizational Care and Support on Emotional and Behavioral Problems of Sheltered Street Children}

A study by Cowan. Beryl Ann (2008) do not support the above observation. The study was aimed at examining the association between traumatic exposure and mental health outcomes in sheltered homeless children. It also investigated the moderating role of perceived social support in the pathway between traumatic exposure and emotional distress. Hierarchical multiple regressions revealed that perceived social support has no influence on mental health morbidity.

\section{RECOMMENDATIONS}

- Government and NGO organizations should start more help lines for street children in metropolitan cities.

- Runaway children need more emotional support and require proper personal counseling.

- Government should provide free and quality education to the street children with low socio economic background.

- Government should start more shelters for street children and their parents. It is very helpful to the homeless families as their children can get more support, strength and well behave under the supervision of their parents.

\section{REFERENCES}

Achenbach, T.M \& Rescorla, L A (2001): Manual for the ASEBA School age forms\& profiles, Burlington, VT: University of Vermont, Research center for children, youth \& Families.

Achenbach, T.M (1965): A factor analytic study of juvenile psychiatric Symptoms Paper presented at society for Research in Child Development, Manneapolis, MN.

Achenbach, T.M (1966): The classification of children's psychiatric symptoms A factor- analytic study. Psychological Monograph, 80, pp 615.

Achenbach, T.M, Howell, C.T, Mc Conaughy, S.H\& stranger, C (1998): Young adult signs of disturbance. Journal of American Academy of Child and Adolescent psychiatry 37, pp 718-727.

Anooshian, Linda J. (2005): Violence and Aggression in the Lives of Homeless children, Journal of Family Violence 20(6), pp 373-387.

Chen, Xiaojin, Thrane, Lisa, Whitbeck, Les B. Johnson\& Kurt (2006): Mental Disorders, Comorbidity, and Post runaway Arrests Among Homeless and Runaway Adolescents Journal of Research on Adolescence 16(3) pp 379-402.

Michael Kerfoot,, Vira Koshyl, Oleksandr Roganov, Kateryna Mikhailichenko, Irina Gorbova \& David Pottage. (2007): The health and well-being of neglected, abused and exploited children: The Kyiv Street Children Project http:// www.Sciencedirect.com

Ramana K.V. (2006): Achenbach's Youth self Report- Development of Telugu, Form. In Kumar D., S.\& Prakash, V(Eds.), Recent Developments in Psychology (pp 55-64) Delhi: Defense Institute of psychological Research, DRDO.

Rashmi, Agarwal. (1999): street children, New Delhi: Shipra press. 


\section{Influence of Organizational Care and Support on Emotional and Behavioral Problems of Sheltered Street Children}

Sandra L. Ayerst, (2003): Depression and Stress in Street Youth. Adolescence, 34(135) pp 567.

Votta, Elizabeth Anne \& Manion, Ian. (2004): Suicide, high-risk behaviors, and coping style in homeless adolescent males' adjustment. Journal of Adolescent Health 34(3) 237-243.

Whitbeck, Les B, Hoyt, Danny R\& Bao, Wa-Ning.(2000): Depressive symptoms and cooccurring depressive symptoms, substance abuse, and conduct problems among runaway and homeless adolescents. Child Development 71(3) pp 721-732.

Whitbeck, Les B, Johnson, Kurt D, Hoyt, Dan R \& Cauce, Ana Mari. (2004): Mental disorder and comorbidity among runaway and homeless adolescents Journal of Adolescent Health 35(2) pp 132-140. 